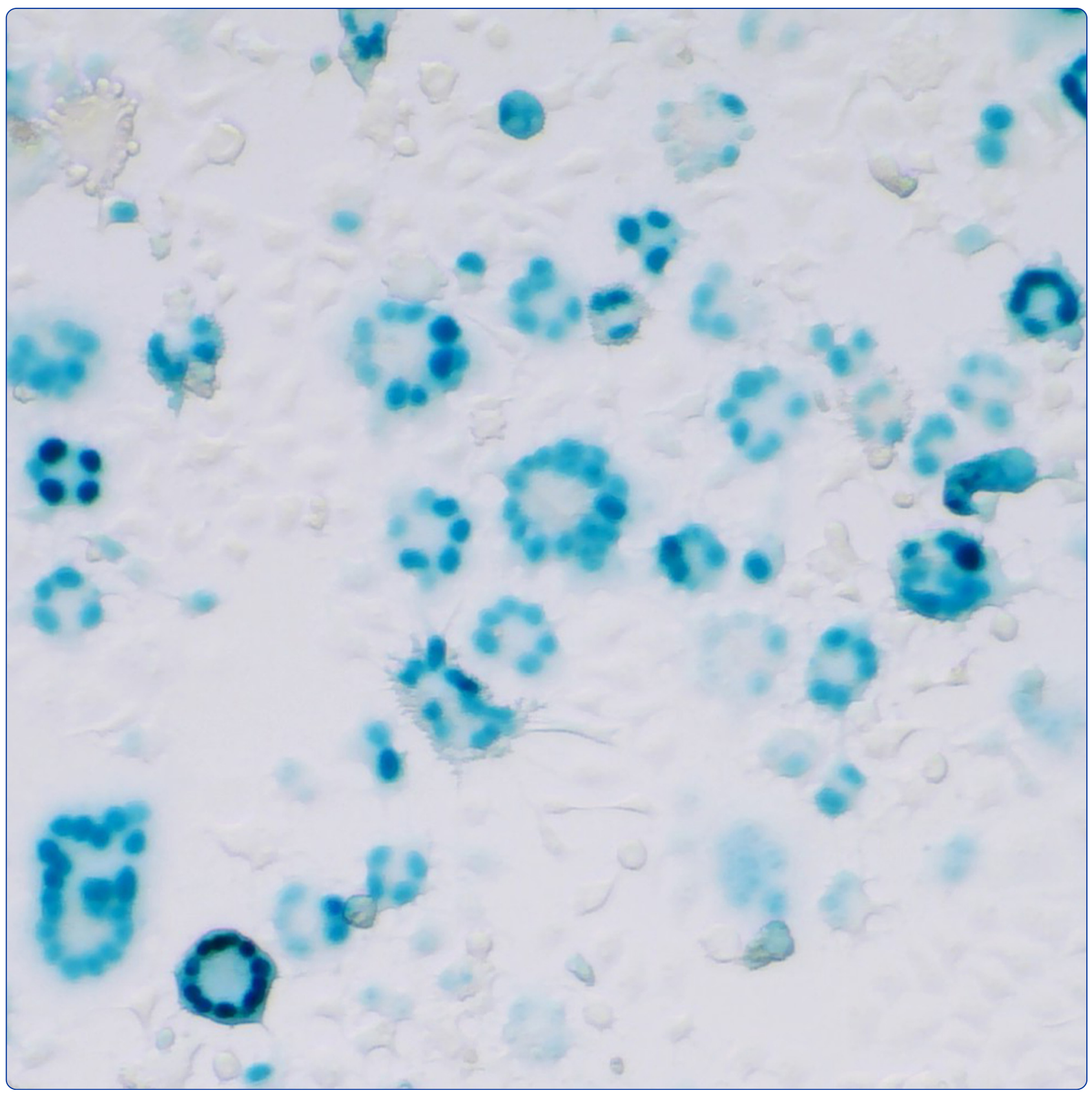

In vitro activity of dolutegravir against wild-type and integrase inhibitor-resistant HIV-2

Smith et al. 


\title{
In vitro activity of dolutegravir against wild-type and integrase inhibitor-resistant HIV-2
}

\author{
Robert A Smith ${ }^{*}$, Dana N Raugi ${ }^{1}$, Charlotte Pan ${ }^{1}$, Papa Salif Sow ${ }^{2}$, Moussa Seydi ${ }^{2}$, James I Mullins ${ }^{3}$, \\ Geoffrey S Gottlieb ${ }^{1,4}$ and the University of Washington-Dakar HIV-2 Study Group
}

\begin{abstract}
Background: Dolutegravir recently became the third integrase strand transfer inhibitor (INSTI) approved for use in HIV-1-infected individuals. In contrast to the extensive dataset for HIV-1, in vitro studies and clinical reports of dolutegravir for HIV-2 are limited. To evaluate the potential role of dolutegravir in HIV-2 treatment, we compared the susceptibilities of wild-type and INSTI-resistant HIV-1 and HIV-2 strains to the drug using single-cycle assays, spreading infections of immortalized T cells, and site-directed mutagenesis.
\end{abstract}

Findings: HIV-2 group A, HIV-2 group B, and HIV-1 isolates from INSTI-naïve individuals were comparably sensitive to dolutegravir in the single-cycle assay (mean $\mathrm{EC}_{50}$ values $=1.9,2.6$, and $1.3 \mathrm{nM}$, respectively). Integrase substitutions E92Q, Y143C, E92Q + Y143C, and Q148R conferred relatively low levels of resistance to dolutegravir in HIV-2ROD9 (2- to 6-fold), but Q148K, E92Q + N155H, T97A + N155H and G140S + Q148R resulted in moderate resistance (10- to 46-fold), and the combination of T97A + Y143C in HIV-2ROD9 conferred high-level resistance ( $>5000$-fold). In contrast, HIV-1 NL4-3 $_{\text {mutants }} \mathrm{E92Q}+\mathrm{N155H}, \mathrm{G140S}+\mathrm{Q} 148 \mathrm{R}$, and T97A + Y143C showed 2-fold, 4-fold, and no increase in $\mathrm{EC}_{50}$, respectively, relative to the parental strain. The resistance phenotypes for $\mathrm{E} 92 \mathrm{Q}+\mathrm{N} 155 \mathrm{H}$, and G140S + Q148R HIV-2ROD9 were also confirmed in spreading infections of CEM-sS cells.

Conclusions: Our data support the use of dolutegravir in INSTI-naïve HIV-2 patients but suggest that, relative to HIV-1, a broader array of replacements in HIV-2 integrase may enable cross-resistance between dolutegravir and other INSTI. Clinical studies are needed to evaluate the efficacy of dolutegravir in HIV-2-infected individuals, including patients previously treated with raltegravir or elvitegravir.

\section{Findings}

Human immunodeficiency virus type 2 (HIV-2) infection is a significant public health problem in West Africa and has been reported in other countries with socioeconomic ties to the region [1]. Dual HIV-1/HIV-2 infection also occurs in areas where the viruses co-circulate [2-6]. Historically, clinical outcomes of antiretroviral therapy in HIV-2 and HIV-1/HIV-2 dually positive patients have been poor, with high rates of immuno-virologic failure and emergent multidrug resistance [7-11]. Newer classes of antiretrovirals (ARV) with anti-HIV-2 activity could represent substantial improvements to the current therapeutic picture $[12,13]$.

\footnotetext{
* Correspondence: smithra@uw.edu

${ }^{1}$ Center for Emerging and Re-emerging Infectious Diseases (CERID) and Department of Medicine, Allergy \& Infectious Diseases, University of Washington, Seattle, WA, USA

Full list of author information is available at the end of the article
}

A growing body of evidence suggests that integrase strand transfer inhibitors (INSTI) might be particularly useful for HIV-2 treatment. Raltegravir and elvitegravir are both potent inhibitors of HIV-2 replication in culture [14-18], and case reports and small case series (primarily involving ARV-experienced individuals) indicate that raltegravir and elvitegravir can reduce HIV-2 viral loads when combined with other suppressive ARV [19-32]. As with HIV-1, changes at integrase residues Y143, Q148 or $\mathrm{N} 155$, together with other secondary replacements in the integrase protein (i.e., E92Q, T97A, G140S, and possibly others), confer resistance to raltegravir in HIV-2 [26,28-35]. The emergence of resistance to elvitegravir has not yet been reported in HIV-2-infected individuals but will likely involve these same three pathways based on studies of HIV-1 [36-50] and the extensive crossresistance seen between raltegravir and elvitegravir in HIV-2 in culture [15,17]. Clinical trials of raltegravir- and 
elvitegravir-containing regimens for first-line HIV-2 treatment are now underway and are expected to yield data within the next few years (NCT01605890, NCT02150993, NCT02180438).

A third strand transfer inhibitor, dolutegravir, was recently approved by the United States Food and Drug Administration (FDA) for use in both INSTI-naïve and INSTI-experienced HIV-1 patients. Although dolutegravir has been extensively evaluated for HIV-1 treatment, few studies have examined its potential use in HIV-2infected individuals. Charpentier and colleagues reported that HIV-2 $2_{\mathrm{ROD}}$, HIV-1 $1_{\mathrm{BRU}}$, and eight HIV-2 isolates from INSTI-naïve patients were comparably susceptible to dolutegravir in spreading infections of peripheral blood mononuclear cells $(\mathrm{PBMC})\left(\mathrm{EC}_{50}=0.2-4 \mathrm{nM}\right)$ and that three HIV-2 isolates from raltegravir-treated individuals with consensus integrase genotypes G140S + Q148R (group A), $\mathrm{G} 140 \mathrm{~T}+\mathrm{Q} 148 \mathrm{R}+\mathrm{N} 155 \mathrm{H}$ (group A), and T97A + Y143C (group $\mathrm{H}$ ) were 63-, 9-, and 5-fold resistant to dolutegravir, respectively, in PBMC [51]. In addition, the manufacturer of dolutegravir (ViiV Healthcare) reported that $\mathrm{EC}_{50}$ values against three clinical isolates of HIV-2 ranged from $0.09 \mathrm{nM}$ to $0.61 \mathrm{nM}$ in PBMC assays, and that combinations of substitutions A153G + N155H + S163G and E92Q + T97A + N155H + S163D in HIV-2 integrase conferred 4-fold decreases in dolutegravir susceptibility, while E92Q + N155H and G140S + Q148R resulted in 8.5-fold and 17-fold decreases, respectively [52].

The ability of dolutegravir to inhibit strains resistant to other INSTI is of particular importance-in HIV-1, mutations Q148H/K/R, together with secondary changes in the integrase protein, confer resistance to dolutegravir in cell culture [38,47,53-55], and other mutations associated with diminished in vitro susceptibility to dolutegravir have been reported [56-61]. In contrast, dolutegravir is fully active against HIV-1 variants bearing Y143 or N155 mutations (with or without secondary changes) in both single-cycle and spreading infection assays [38,47,53-55], although it should be noted that Y143 and N155 mutants have been observed in raltegravir-experienced patients who subsequently failed dolutegravir-based regimens $[62,63]$. In the VIKING-3 trial, dolutegravir response rates $(<50$ HIV-1 RNA copies/ml at week 24) declined from $79 \%$ $(\mathrm{n}=100 / 126)$ for patients without Q148 mutations at baseline (including those with $\mathrm{N} 155 \mathrm{H}, \mathrm{Y} 143 \mathrm{C} / \mathrm{H} / \mathrm{R}, \mathrm{T} 66 \mathrm{~A}$, E92Q, or historical evidence of INSTI resistance), to $58 \%$ (21/36) for patients with Q148 plus one additional secondary mutation, to $24 \%(5 / 21)$ for those with Q148 plus two or more secondary mutations [64]. Importantly, drug resistance testing is not widely available in West Africa, and thus, dolutegravir usage in many HIV-2-infected patients, including INSTI-experienced individuals, will depend on an algorithmic approach to treatment. To date, there are only two reports of dolutegravir treatment for
HIV-2 infection ([65,66]; $\mathrm{n}=2$ and 13 patients, respectively), with limited duration of follow-up.

In the present study, we examined the activity of dolutegravir against wild-type and INSTI-resistant HIV2 strains using an indicator cell assay that restricts viral replication to a single cycle [15]. This methodology enables a direct comparison of HIV-1 and HIV-2 drug susceptibility while avoiding potential confounders such as differences in replication rates, infectivity, cytopathic potential and cell-to-cell spread.

We initially compared the dolutegravir sensitivities of viruses derived from two prototypic full-length molecular clones: pNL4-3 (HIV-1 group $\mathrm{M}$, subtype B) and pROD9 (HIV-2 group A). In head-to-head single-cycle assays, these two strains showed nearly identical doseresponse profiles (Figure 1A). Over multiple assays runs, the mean $\mathrm{EC}_{50}$ values for dolutegravir ( \pm standard deviation) were $1.5 \pm 0.6 \mathrm{nM}$ for HIV-1 $1_{\mathrm{NL} 4-3}$ and $2.3 \pm$ $0.7 \mathrm{nM}$ for HIV-2 $2_{\text {ROD9 }}(\mathrm{n}=14$ and 24 determinations, respectively). Dolutegravir was 3.6-fold more potent than raltegravir and 9.1-fold more potent than elvitegravir against HIV-2 $2_{\text {ROD9 }}$ (Figure 1B). Other isolates from ARV-naïve individuals displayed levels of dolutegravir sensitivity comparable to HIV-1 $1_{\mathrm{NL} 4-3}$ and HIV-2 $2_{\text {ROD9 }}$ (Figure $1 \mathrm{C}$ ). The aggregate $\mathrm{EC}_{50}$ values for HIV-1, HIV2 group A, and HIV-2 group B were $1.3 \pm 0.2 \mathrm{nM}, 1.9 \pm$ $0.5 \mathrm{nM}$, and $2.6 \pm 0.9 \mathrm{nM}$, respectively. When subjected to a one-way ANOVA, only the comparison between HIV-1 and HIV-2 group B reached statistical significance $(\mathrm{p}<0.05)$; this modest difference was attributable to the slightly higher $\mathrm{EC}_{50}$ for HIV-2 $\mathrm{EHO}_{\mathrm{EH}}(3.6 \pm 1.9 \mathrm{nM})$ (Figure 1C). Notably, HIV-2 $\mathrm{EHO}$ integrase contains a glutamate at position 146, whereas other HIV-2 isolates (as well as HIV-1) encode glutamine at this site $[67,68]$. Substitutions at Q146 have been observed in HIV-1 following in vitro selections with elvitegravir and other, investigational INSTI $[18,69,70]$. To our knowledge, Q146 mutations have not been observed in HIV-2 variants selected in culture, nor have they been reported in HIV-2 patients treated with INSTI-based regimens.

To examine potential resistance pathways in HIV-2, we tested the activity of dolutegravir against a panel of site-directed mutants of HIV-2 $2_{\text {ROD9 }}$ using the singlecycle assay. These variants contained amino acid replacements in the integrase protein that are associated with raltegravir and elvitegravir treatment; their phenotypes with respect to raltegravir and elvitegravir susceptibility have been reported elsewhere $[14,15]$. Single amino acid changes T97A, G140S, Q148H and N155H had no significant effect on dolutegravir sensitivity $(p>0.05$, ANOVA; Figure 2A). In contrast, mutants E92Q, Y143C, $\mathrm{E} 92 \mathrm{Q}+\mathrm{Y} 143 \mathrm{C}, \mathrm{Q} 148 \mathrm{~K}$, and Q148R were resistant to dolutegravir, with $\mathrm{EC}_{50}$ values 2.3-9.3-fold greater than that of the parental strain (Figure 2A), and variants 

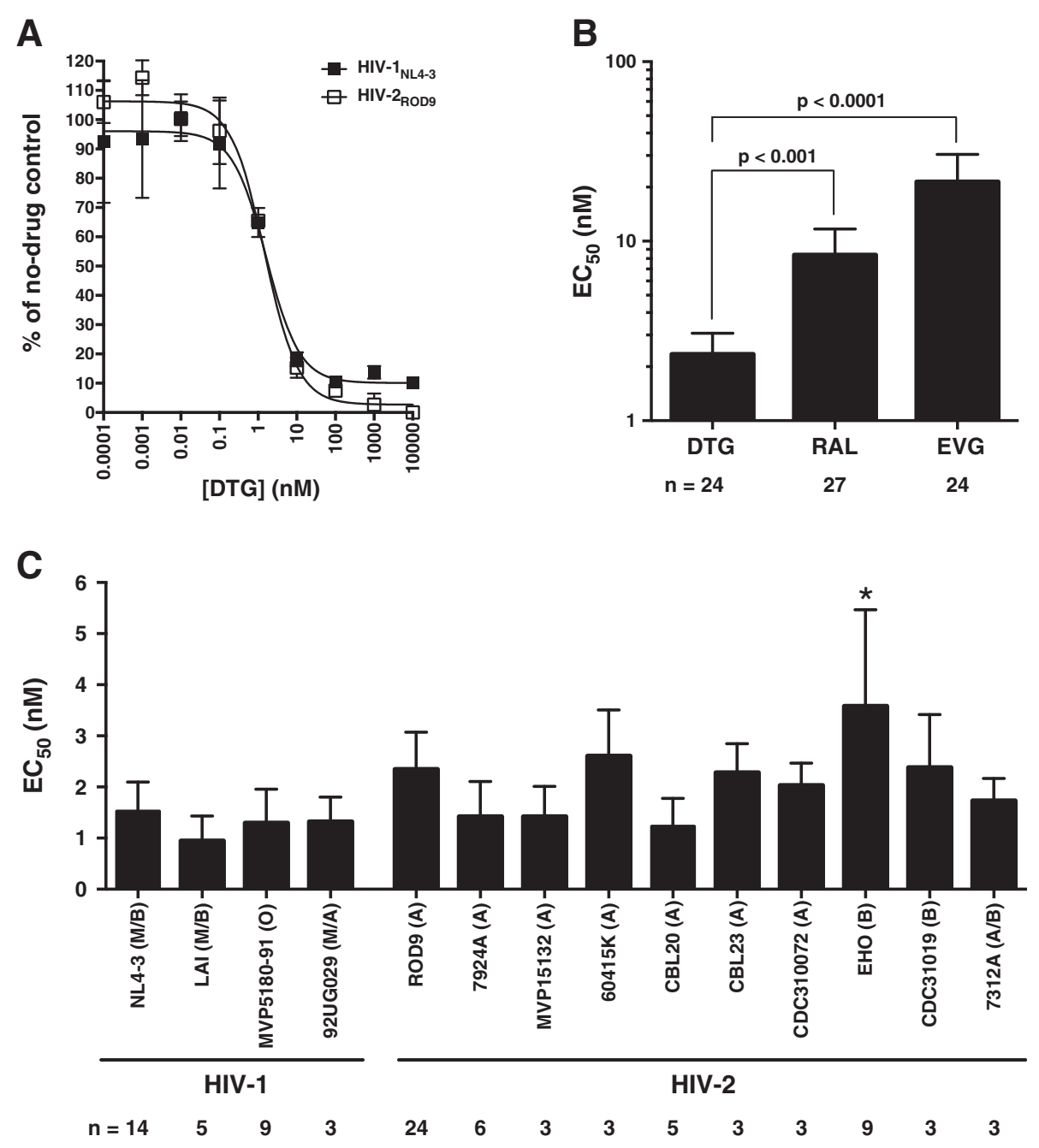

Figure 1 Susceptibility of wild-type HIV-1 and HIV-2 isolates to dolutegravir in the single-cycle assay. (A) Representative dose-response

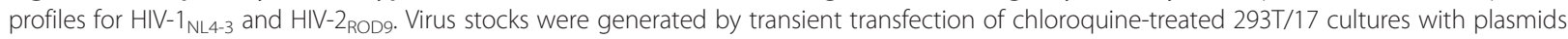
pNL4-3 and pROD9, respectively. Dolutegravir was obtained from Selleck Chemicals, Inc. Titers are expressed as the percentage of no-drug (solvent-only) controls and are the means of two independent cultures at each drug concentration. Curve fits were generated using the sigmoid dose-response function of Prism version 6.0 (GraphPad Software, Inc.). (B) Comparison of the activity of dolutegravir (DTG), raltegravir (RAL), and elvitegravir (EVG) against wild-type HIV-2RODg. Values for RAL and EVG include data from two previously-published studies of HIV-2 from our group $[14,15]$ plus additional determinations; all data were obtained using the single-cycle assay. Bars indicate mean $50 \%$ effective concentrations ( $\left.\mathbb{E C}_{50}\right)$; the number of independent determinations ( $n$ ) for each strain is shown below the $x$-axis. $P$ values were obtained via analysis of variance (ANOVA) of $\log _{10}$-transformed $E_{50}$ values with Tukey's post test (Prism v6.0). No cytotoxic effects were observed in dolutegravir-treated MAGIC-5A cultures at concentrations as high as 10,000 nM. (C) Activity of dolutegravir against wild-type HIV-1 and HIV-2 isolates. Group/subtype designations are shown in parentheses. HIV-1 ${ }_{\mathrm{NL4}-3}$ and HIV-2 $2_{\mathrm{ROD}}$ were generated as in panel A. HIV-2 $2_{\mathrm{EHO}}$ was kindly provided by Jan McClure (University of Washington). The remaining isolates were obtained from the National Institutes of Health AIDS Reagent Program (www.aidsreagent.org). ${ }^{*}$, significantly greater than HIV-2 ROD9, HIV-2 MVP15132, HIV-2 CBL20, and all HIV-1 isolates listed ( $p<0.05$, ANOVA with Tukey's post test). In all panels, error bars indicate standard deviations.

$\mathrm{E} 92 \mathrm{Q}+\mathrm{N} 155 \mathrm{H}, \quad \mathrm{T} 97 \mathrm{~A}+\mathrm{N} 155 \mathrm{H}$ and $\mathrm{G} 140 \mathrm{~S}+\mathrm{Q} 148 \mathrm{R}$ exhibited 11-33-fold resistance to the drug $(\mathrm{p}<0.05$, ANOVA; Figure 2A and B). In experiments with T97A + Y143C HIV-2 $2_{\text {ROD9, }}$, dolutegravir concentrations as high as $10 \mu \mathrm{M}$ failed to reduce viral replication by $50 \%$ (Figure $2 \mathrm{~A}$ and $\left.\mathrm{C} ; \mathrm{EC}_{50}>10 \mu \mathrm{M}\right)$, although modest dose-dependent inhibition was apparent at doses $\geq 100 \mathrm{nM}$ (Figure 2C).
Altogether, nine of the 13 HIV-2 integrase mutants tested were resistant to dolutegravir in the single-cycle assay (Figure 2A).

We also evaluated the dolutegravir sensitivities of $\mathrm{E} 92 \mathrm{Q}+$ $\mathrm{N} 155 \mathrm{H}, \mathrm{T} 97 \mathrm{~A}+\mathrm{Y} 143 \mathrm{C}$, and G140S + Q148R HIV-2 ROD9 in three-day spreading infections of immortalized $\mathrm{T}$ cells (CEM-ss). These assays were preformed as previously 
A

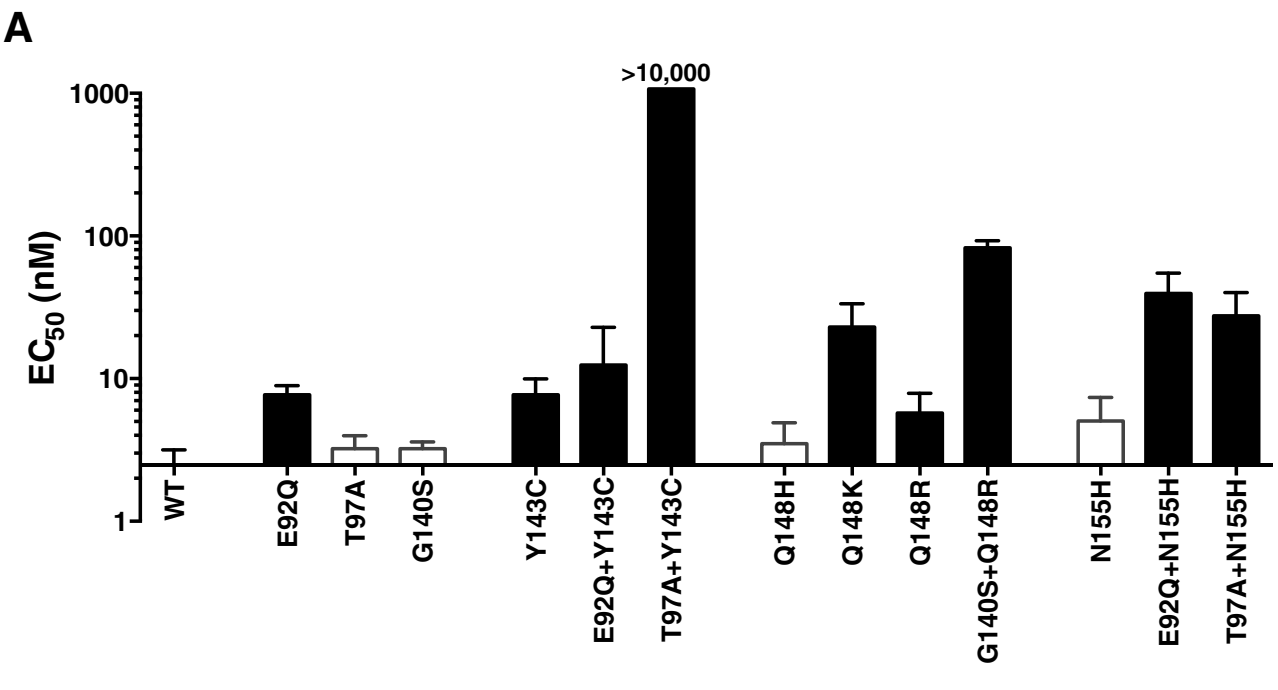

$\begin{array}{llllllllllllll}\mathrm{n}=20 & 3 & 3 & 3 & 3 & 5 & 9 & 4 & 4 & 4 & 3 & 3 & 3 & 3\end{array}$

B

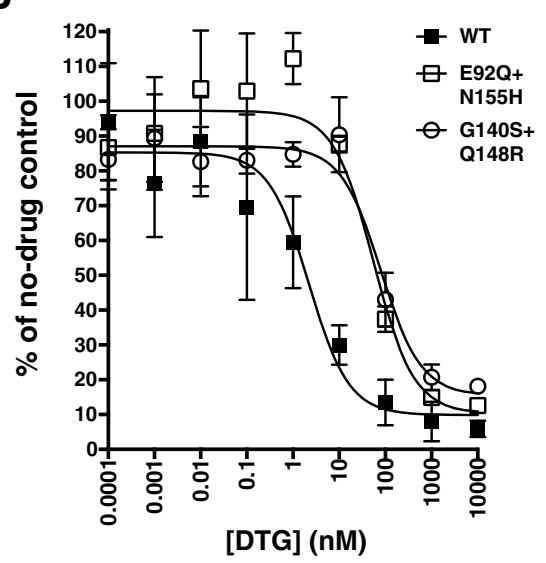

C

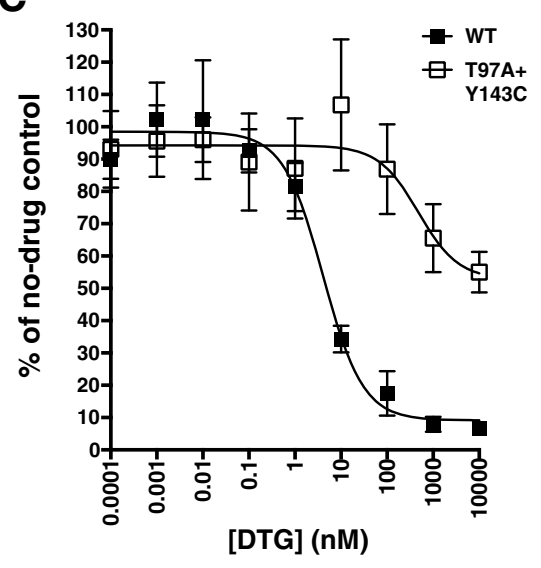

D

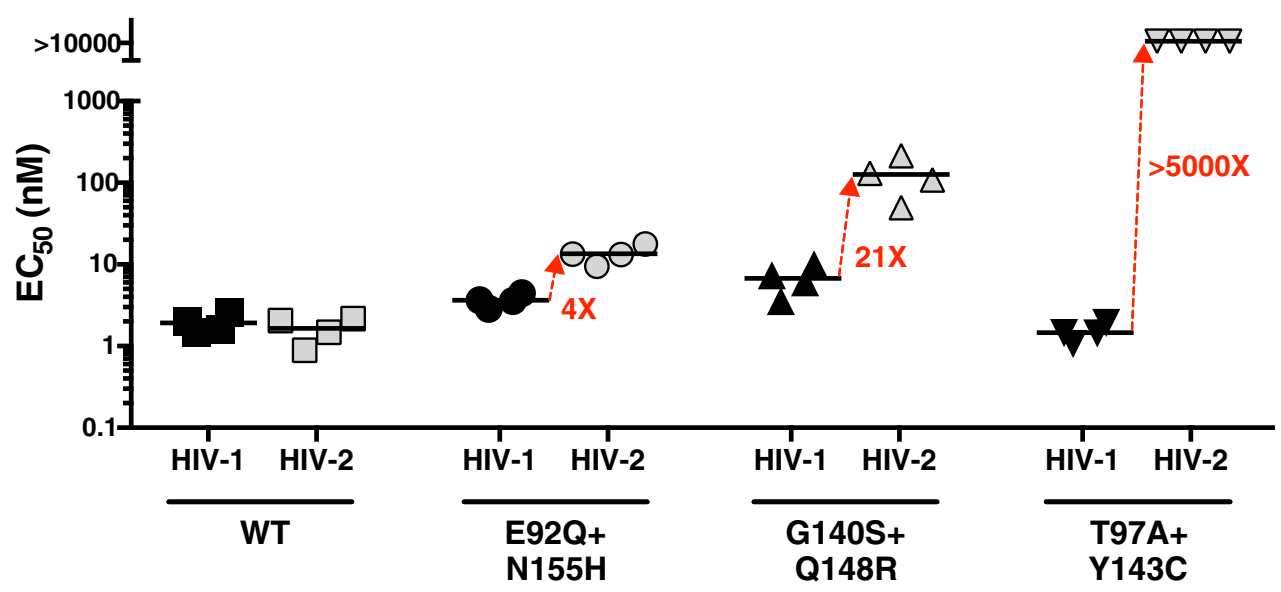

Figure 2 (See legend on next page.) 
(See figure on previous page.)

Figure 2 Antiviral activity of dolutegravir against site-directed mutants of HIV-1 and HIV-2 integrase in the single-cycle assay. (A) $\mathrm{EC}_{50}$ values for wild-type (WT) HIV-2RODg and HIV-2RODg integrase mutants generated in the full-length pROD9 molecular clone. Shaded bars indicate strains that are significantly different from wild-type $\left(p<0.05\right.$, ANOVA of $\log _{10}$-transformed $\mathrm{EC}_{50}$ values with Tukey's post test; Prism v6.0). The number of independent determinations (n) for each strain is shown below the $x$-axis. (B) and (C) Representative dose-response profiles for WT, $\mathrm{E} 92 \mathrm{Q}+\mathrm{N155H}, \mathrm{G} 140 \mathrm{~S}+\mathrm{Q} 148 \mathrm{R}$ and T97A + Y143C HIV-2 ROD9. Data are the means of three independent cultures at each dose of dolutegravir (DTG). Curve fits were generated as described in Figure 1A. (D) Comparative analysis of equivalent site-directed mutants of HIV-1 and HIV-2 integrase. Each point is the result of a single dose-response assay performed as described in Figure $1 \mathrm{~A}$. Horizontal bars indicate the mean $\mathrm{EC}_{50}$ values for each strain. Red arrows and text indicate fold increases in the mean $\mathrm{EC}_{50}$ values for HIV-2 relative to HIV-1. ANOVA results for these data are described in the main text. In all panels, error bars represent standard deviations.

described for the MT-2 T cell line [14]. The resultant $\mathrm{EC}_{50}$ values for the parental strain, $\mathrm{E} 92 \mathrm{Q}+\mathrm{N} 115 \mathrm{H}$, and G140S + Q148R were 0.24, 2.1 and $73 \mathrm{nM}$, respectively, indicating 8.8-fold resistance to dolutegravir for $\mathrm{E} 92 \mathrm{Q}+\mathrm{N} 115 \mathrm{H}$ and 300-fold resistance for G140S + Q148R. Despite repeated attempts using high multiplicities of infection $(\geq 0.1)$ and prolonged incubation times (up to seven days), CEM-ss cultures inoculated with T97A + Y143C HIV-2 $2_{\text {ROD9 }}$ failed to produce detectable levels of infectious virus, indicating a severe fitness defect. This result is consistent with the poor replication capacity previously reported for T97A + Y143C HIV-2 ROD9 [15].

Lastly, we performed a head-to-head comparison of the phenotypes conferred by $\mathrm{E} 92 \mathrm{Q}+\mathrm{N} 155 \mathrm{H}, \mathrm{G} 140 \mathrm{~S}+$ Q148R, and T97A + Y143C in HIV-1 $1_{\mathrm{NL} 4-3}$ and HIV$2_{\mathrm{ROD} 9}$ in the single-cycle assay. G140S + Q148R resulted in slight resistance to dolutegravir in $\mathrm{HIV}_{-1} 1_{\mathrm{NL4}-3}$ (3.5fold; $\mathrm{p}<0.01$, ANOVA), whereas $\mathrm{E} 92 \mathrm{Q}+\mathrm{N} 155 \mathrm{H}$ and T97A + Y143C had no statistically significant effect in the HIV-1 $1_{\text {NL4-3 }}$ background (Figure $2 \mathrm{D}$ ). These data are entirely consistent with previous studies of HIV-1 $[38,47,53,54]$. In contrast, HIV-2 ${ }_{\text {ROD9 }}$ mutants E92Q + $\mathrm{N} 155 \mathrm{H}, \mathrm{G} 140 \mathrm{~S}+\mathrm{Q} 148 \mathrm{R}$, and T97A + Y143C were all resistant to dolutegravir $(\mathrm{p}<0.0001$, ANOVA) and showed $\mathrm{EC}_{50}$ values 4 -, 21 - and $>5000$-fold greater than those seen for equivalent mutants of HIV-1 $1_{\mathrm{NL} 4-3}$, respectively (Figure 2D). $\mathrm{EC}_{50}$ and fold change values for all HIV-1 $\mathrm{NL4}_{\mathrm{NL}-3}$ and HIV- $2_{\text {ROD9 }}$ integrase mutants tested in this study, together with the corresponding $\mathrm{EC}_{50}$ values for the parental wild-type clones, are compiled in Table 1.

Taken together, our results indicate that prototypic HIV-1 and HIV-2 strains, as well as HIV-1 and HIV-2 isolates from INSTI-naïve individuals, are comparably sensitive to dolutegravir in a single cycle of viral replication in MAGIC-5A indicator cells (Figure 1). These findings complement previous data from spreading infections of PBMC [51]-using a different methodology and target cell type-and suggest that dolutegravir would be an appropriate treatment choice for INSTI-naïve HIV-2 patients when combined with other HIV-2-active ARV. We also report the effects of raltegravir-associated mutations on dolutegravir susceptibility using site-directed mutagenesis of genetically-defined HIV-1 and HIV-2 molecular clones (pNL4-3 and pROD9, respectively).
Our analysis shows that equivalent amino acid changes in the integrase proteins of HIV-1 and HIV-2 can have differing effects on dolutegravir susceptibility (Figure 2D) and that, in HIV-2 $2_{\text {ROD9 }}$, integrase changes Q148K, T97A + $\mathrm{Y} 143 \mathrm{C}, \mathrm{E} 92 \mathrm{Q}+\mathrm{N} 155 \mathrm{H}, \mathrm{T} 97 \mathrm{~A}+\mathrm{N} 155 \mathrm{H}$, and $\mathrm{G} 140 \mathrm{~S}+$ Q148R confer moderate to high levels of dolutegravir resistance ( $\geq 10$-fold; Figure $2 \mathrm{~A}-\mathrm{C}$ and Table 1$)$. We cannot exclude the possibility that the resistance levels observed in our site-directed HIV-2 mutants are specific to the ROD9 molecular clone, as the genetic context within integrase can have a substantial impact on the phenotypic expression of INSTI resistance [71,72]. For example, in the aforementioned study by Charpentier et al.

Table 1 Compilation of $\mathrm{EC}_{50}$ and fold change values for site-directed mutants of HIV-2 $2_{\text {ROD } 9}$ and HIV-1 ${ }_{\text {NL4-3 }}$ integrase

\begin{tabular}{lllll}
\hline HIV Type & Strain & EC $_{\mathbf{5 0}}$ for DTG $(\mathbf{n M})^{\mathbf{a}}$ & $\mathbf{n}^{\mathbf{b}}$ & Fold Change $^{\mathbf{c}}$ \\
\hline HIV-2 & Wild-type & $2.3 \pm 0.7$ & 24 & \\
& E92Q & $\mathbf{7 . 7} \pm \mathbf{1 . 2}$ & 3 & 3 \\
& T97A & $3.2 \pm 0.8$ & 3 & 1 \\
& G140S & $3.2 \pm 0.8$ & 3 & 1 \\
& Y143C & $\mathbf{7 . 7} \pm \mathbf{2 . 2}$ & 3 & 3 \\
Q148H & $3.5 \pm 1.4$ & 4 & 1 \\
& Q148K & $\mathbf{2 3} \pm \mathbf{1 0}$ & 4 & 10 \\
& Q148R & $\mathbf{5 . 7} \pm \mathbf{2 . 1}$ & 4 & 2 \\
& N155H & $5.0 \pm 2.4$ & 3 & 2 \\
& E92Q + Y143C & $\mathbf{1 5} \pm \mathbf{1 0}$ & 5 & 6 \\
& T97A + Y143C & $>\mathbf{1 0 0 0 0}$ & 13 & $>5000$ \\
& G140S + Q148R & $\mathbf{1 0 8} \pm \mathbf{5 4}$ & 7 & 46 \\
& E92Q + N155H & $\mathbf{2 5} \pm \mathbf{1 7}$ & 7 & 10 \\
& T97A + N155H & $\mathbf{2 7} \pm \mathbf{1 3}$ & 3 & 12 \\
Wild-type & $1.5 \pm 0.6$ & 14 & \\
TIV7A + Y143C & $1.5 \pm 0.4$ & 4 & 1 \\
G140S + Q148R & $\mathbf{6 . 8} \pm \mathbf{2 . 7}$ & 4 & 4 \\
E92Q + N155H & $\mathbf{3 . 6} \pm \mathbf{0 . 7}$ & 4 & 2
\end{tabular}

${ }^{a} 50 \%$ effective concentration of dolutegravir (DTG) as measured in the MAGIC-5A single-cycle assay. Values were compiled from the data used to generate Figures $2 A$ and $2 D$ and are expressed as means \pm standard deviations. Numbers shown in bold type are significantly greater than the values for the corresponding wild-type strains ( $p<0.05$; ANOVA of $\log _{10}$-transformed $\mathrm{EC}_{50}$ values with Tukey's post-test; performed in Prism version 6.0, GraphPad Software, Inc.).

${ }^{\mathrm{b}}$ Number of independent determinations for each strain.

${ }^{\mathrm{c}}$ Fold change in $\mathrm{EC}_{50}$ relative to the corresponding wild-type strain. 
[51], a group H HIV-2 isolate with T97A + Y143C was only 5-fold resistant to dolutegravir (this isolate differs from HIV-2 $2_{\text {ROD9 }}$ at 24 of 293 amino acid sites in the integrase protein). In addition, the roles of novel INSTIassociated changes (i.e, H51Y, G118R, F121Y, E138A/K, and R263K; [26,34,57-61,63,73]) remain to be determined in HIV-2, and the level of dolutegravir resistance in vitro that correlates with virologic failure in HIV-2infected patients is unknown. Nonetheless, our findings suggest that, relative to HIV-1, a broader array of amino acid changes in HIV-2 integrase might facilitate crossresistance between dolutegravir and other INSTI. Phenotypic drug resistance testing of HIV-2 isolates from raltegravir- and elvitegravir-treated patients should be performed as these drugs become more widely available in West Africa, and studies of dolutegravir-based regimens should be conducted in HIV-2-infected individuals, including patients previously treated with other INSTI.

\section{Abbreviations}

HIV-1: Human immunodeficiency virus type 1; HIV-2: Human immunodeficiency virus type 2; ARV: antiretroviral; INSTI: Integrase strand transfer inhibitor; $\mathrm{EC}_{50}$ : 50\% effective concentration; DTG: Dolutegravir; RAL: Raltegravir; EVG: Elvitegravir; FDA: Food and drug administration; ANOVA: Analysis of variance.
\end{abstract}

\section{Competing interests}

The authors declare that they have no competing interests.

\section{Authors' contributions}

RS and GG conceived the study, designed the experiments and prepared the final version of the manuscript. RS performed the experiments, analyzed the data, and drafted the manuscript. DR and CP helped conduct the virologic assays. GG, PS, MS and JM provided intellectual input throughout the study and helped interpret the data. All authors read and approved the final manuscript.

\section{Acknowledgements}

These studies were supported by grants to GSG from the National Institutes of Health/National Institute of Allergy and Infectious Diseases (NIH/NIAID; 2R01-AI060466), the UW Center For AIDS Research (CFAR, an NIH-funded program; P30 Al027757), and the UW Royalty Research Fund (A92723). We thank the NIH AIDS Research and Reference Reagent Program for providing wild-type HIV-1 and HIV-2 strains. Additional UW-Dakar HIV-2 Study Group members are as follows: Macoumba Toure, Selly Ba, Ndeye Mery Dia Badiane, Louise Fortes, Cheikh T. Ndour, Jacques Ndour, Fatou Niasse, Fatima Sall, Fatou Traore, Khadim Faye, Sophie Chablis, Marie Pierre Sy, Bintou Diaw, Mbaye Ndoye, Amadou Bale Diop, Marianne Fadam Diome (Clinique des Maladies Infectieuses Ibrahima DIOP Mar, Centre Hospitalier Universitaire de Fann, Universite' Cheikh Anta Diop de Dakar, Dakar, Senegal); Alassane Niang, ElHadji Ibrahima Sall, Ousseynou Cisse, Jean Philippe Diatta, Raphael Bakhoum, Juliette Gomis, (Région Médicale de Ziguinchor, Ziguinchor, Casamance, Senegal), Stephen Hawes, Donna Kenney, Joshua Stern, Qinghua Feng, John Lin, Steve Cherne, Nancy Kiviat, Brad Church, Matthew Coyne, Alexandra Hernandez, Alexandra Montano, Kara Parker, Kate Parker, Lindsey Blankenship, Mariah Oakes, Julia Olson, and Sally Leong (University of Washington, Seattle, Washington).

\section{Author details}

${ }^{1}$ Center for Emerging and Re-emerging Infectious Diseases (CERID) and Department of Medicine, Allergy \& Infectious Diseases, University of Washington, Seattle, WA, USA. ${ }^{2}$ Service des Maladies Infectieuses, CHNU de Fann, Dakar, Senegal. ${ }^{3}$ Departments of Microbiology, Medicine and Laboratory Medicine, University of Washington, Seattle, WA, USA. ${ }^{4}$ Department of Global Health, University of Washington, Seattle, WA, USA.
Received: 21 November 2014 Accepted: 21 January 2015

Published online: 05 February 2015

\section{References}

1. de Silva TI, Cotten M, Rowland-Jones SL. HIV-2: the forgotten AIDS virus. Trends Microbiol. 2008;16:588-95.

2. Cot MC, Poulain M, Delagneau JF, Peeters M, Brun-Vezinet F. Dual HIV-1 and HIV-2 infection in West Africa supported by synthetic peptide analysis. AIDS Res Hum Retroviruses. 1988;4:239-41.

3. Evans LA, Moreau J, Odehouri K, Seto D, Thomson-Honnebier G, Legg H, et al. Simultaneous isolation of HIV-1 and HIV-2 from an AIDS patient. Lancet. 1988;2:1389-91.

4. Rayfield M, De Cock K, Heyward W, Goldstein L, Krebs J, Kwok S, et al. Mixed human immunodeficiency virus (HIV) infection in an individual: demonstration of both HIV type 1 and type 2 proviral sequences by using polymerase chain reaction. J Infect Dis. 1988;158:1170-6.

5. Heitzinger K, Sow PS, Dia Badiane NM, Gottlieb GS, N'Doye I, Toure M, et al. Trends of HIV-1, HIV-2 and dual infection in women attending outpatient clinics in Senegal, 1990-2009. Int J STD AIDS. 2012;23:710-6.

6. Raugi DN, Gottlieb GS, Sow PS, Toure M, Sall F, Gaye A, et al. HIV-1 outcompetes HIV-2 in dually infected Senegalese individuals with low CD4(+) cell counts. AIDS. 2013;27:2441-50.

7. Gottlieb GS, Badiane NM, Hawes SE, Fortes L, Toure M, Ndour CT, et al. Emergence of multiclass drug-resistance in HIV-2 in antiretroviral-treated individuals in Senegal: implications for HIV-2 treatment in resource-limited West Africa. Clin Infect Dis. 2009:48:476-83.

8. Charpentier C, Eholie S, Anglaret X, Bertine M, Rouzioux C, Avettand-Fenoel $\mathrm{V}$, et al. Genotypic resistance profiles of HIV-2-treated patients in West Africa. AIDS. 2014;28:1161-9.

9. Okomo U, Togun T, Oko F, Peterson $K$, Townend J, Peterson I, et al. Treatment outcomes among HIV-1 and HIV-2 infected children initiating antiretroviral therapy in a concentrated low prevalence setting in West Africa. BMC Pediatr. 2012;12:95.

10. Jallow S, Alabi A, Sarge-Njie R, Peterson K, Whittle H, Corrah T, et al. Virological response to highly active antiretroviral therapy in patients infected with human immunodeficiency virus type 2 (HIV-2) and in patients dually infected with HIV-1 and HIV-2 in the Gambia and emergence of drug-resistant variants. J Clin Microbiol. 2009;47:2200-8.

11. Benard A, van Sighem A, Taieb A, Valadas E, Ruelle J, Soriano V, et al. Immunovirological response to triple nucleotide reverse-transcriptase inhibitors and ritonavir-boosted protease inhibitors in treatment-naive HIV-2infected patients: The ACHIEV2E Collaboration Study Group. Clin Infect Dis. 2011;52:1257-66.

12. Menendez-Arias $L$, Alvarez $M$. Antiretroviral therapy and drug resistance in human immunodeficiency virus type 2 infection. Antiviral Res. 2014;102:70-86.

13. Peterson $\mathrm{K}$, Rowland-Jones $\mathrm{S}$. Novel agents for the treatment of HIV-2 infection. Antivir Ther. 2012;17:435-8.

14. Smith RA, Raugi DN, Kiviat NB, Hawes SE, Mullins Jl, Sow PS, et al. Phenotypic susceptibility of HIV-2 to raltegravir: integrase mutations Q148R and N155H confer raltegravir resistance. AIDS. 2011;25:2235-41.

15. Smith RA, Raugi DN, Pan C, Coyne M, Hernandez A, Church B, et al. Three main mutational pathways in HIV-2 lead to high-level raltegravir and elvitegravir resistance: implications for emerging HIV-2 treatment regimens. PLoS One. 2012;:e45372.

16. Roquebert B, Damond F, Collin G, Matheron S, Peytavin G, Benard A, et al, HIV-2 integrase gene polymorphism and phenotypic susceptibility of HIV-2 clinical isolates to the integrase inhibitors raltegravir and elvitegravir in vitro. J Antimicrob Chemother. 2008;62:914-20.

17. Andreatta K, Miller MD, White KL. HIV-2 antiviral potency and selection of drug resistance mutations by the integrase strand transfer inhibitor elvitegravir and NRTIs emtricitabine and tenofovir in vitro. J Acquir Immune Defic Syndr. 2013;62:367-74.

18. Shimura K, Kodama E, Sakagami Y, Matsuzaki Y, Watanabe W, Yamataka K, et al. Broad antiretroviral activity and resistance profile of the novel human immunodeficiency virus integrase inhibitor elvitegravir (JTK-303/GS-9137). J Virol. 2008;82:764-74.

19. Peterson K, Ruelle J, Vekemans M, Siegal FP, Deayton JR, Colebunders R. The role of raltegravir in the treatment of HIV-2 infections: evidence from a case series. Antivir Ther. 2012;17:1097-100.

20. Doroana M, Pinheiro C, Oliveira J, Mansinho K, Germano I, Fonseca P, et al. Comparing treatment of HIV-1 and HIV-2 patients with raltegravir plus OBT. 
6th International AIDS Society Conference on HIV Pathogenesis, Treatment and Prevention; 17-20 July 2011; Rome, Italy.

21. Francisci D, Martinelli L, Weimer LE, Zazzi M, Floridia M, Masini G, et al. HIV-2 infection, end-stage renal disease and protease inhibitor intolerance: which salvage regimen? Clin Drug Investig. 2011;31:345-9.

22. Zheng Y, Lambert C, Arendt V, Seguin-Devaux C. Virological and immunological outcomes of elvitegravir-based regimen in a treatment-naive HIV-2-infected patient. AIDS. 2014;28:2329-31.

23. Povoas D, Lino S, Manata MJ, Machado J, Maltez F. Raltegravir in the treatment of HIV-2 infection: a report of eight cases. Int J Med Pharm Case Rep. 2015;2:36-43.

24. Wandeler $G$, Furrer $H$, Rauch $A$. Sustained virological response to a raltegravir-containing salvage therapy in an HIV-2-infected patient. AIDS. 2011;25:2306-8

25. Armstrong-James D, Stebbing J, Scourfield A, Smit E, Ferns B, Pillay D, et al. Clinical outcome in resistant HIV-2 infection treated with raltegravir and maraviroc. Antiviral Res. 2010;86:224-6.

26. Cavaco-Silva J, Abecasis A, Miranda AC, Pocas J, Narciso J, Aguas MJ, et al. HIV-2 integrase polymorphisms and longitudinal genotypic analysis of HIV-2 infected patients failing a raltegravir-containing regimen. PLoS One. 2014;9:e92747.

27. Damond F, Lariven S, Roquebert B, Males S, Peytavin G, Morau G, et al. Virological and immunological response to HAART regimen containing integrase inhibitors in HIV-2-infected patients. AIDS. 2008;22:665-6.

28. Garrett N, Xu L, Smit E, Ferns B, El-Gadi S, Anderson J. Raltegravir treatment response in an HIV-2 infected patient: a case report. AIDS. 2008;22:1091-2.

29. Charpentier C, Roquebert B, Delelis O, Larrouy L, Matheron S, Tubiana R, et al. Hot spots of integrase genotypic changes leading to HIV-2 resistance to raltegravir. Antimicrob Agents Chemother. 2011;55:1293-5.

30. Xu L, Anderson J, Garrett N, Ferns B, Wildfire A, Cook P, et al. Dynamics of raltegravir resistance profile in an HIV type 2-infected patient. AIDS Res Hum Retroviruses. 2009;25:843-7.

31. Roquebert B, Blum L, Collin G, Damond F, Peytavin G, Leleu J, et al. Selection of the Q148R integrase inhibitor resistance mutation in a failing raltegravir containing regimen. AIDS. 2008;22:2045-6.

32. Trevino A, de Mendoza C, Caballero E, Rodriguez C, Parra P, Benito R, et al. Drug resistance mutations in patients infected with HIV-2 living in Spain. J Antimicrob Chemother. 2011;66:1484-8.

33. Salgado M, Toro C, Simon A, Garrido C, Blanco F, Soriano V, et al. Mutation $\mathrm{N} 155 \mathrm{H}$ in HIV-2 integrase confers high phenotypic resistance to raltegravir and impairs replication capacity. J Clin Virol. 2009;46:173-5.

34. Trevino A, Parra P, Cabezas T, Lozano AB, Garcia-Delgado R, Force L, et al. Drug resistance mutations in HIV-2 patients failing raltegravir - extent of cross-resistance to dolutegravir. Antivir Ther. 2013;18 Suppl 1:A105.

35. Ni XJ, Delelis O, Charpentier C, Storto A, Collin G, Damond F, et al. G140S/ Q148R and N155H mutations render HIV-2 Integrase resistant to raltegravir whereas Y143C does not. Retrovirology. 2011;8:68.

36. Grobler JA, Hazuda DJ. Resistance to HIV integrase strand transfer inhibitors: in vitro findings and clinical consequences. Curr Opin Virol. 2014;8C:98-103.

37. Hurt CB, Sebastian J, Hicks CB, Eron JJ. Resistance to HIV integrase strand transfer inhibitors among clinical specimens in the United States, 2009-2012. Clin Infect Dis. 2014:58:423-31.

38. Abram ME, Hluhanich RM, Goodman DD, Andreatta KN, Margot NA, Ye L, et al. Impact of primary elvitegravir resistance-associated mutations in HIV-1 integrase on drug susceptibility and viral replication fitness. Antimicrob Agents Chemother. 2013:57:2654-63.

39. Menendez-Arias L. Molecular basis of human immunodeficiency virus type 1 drug resistance: overview and recent developments. Antiviral Res. 2013;98:93-120.

40. Huang W, Frantzell A, Fransen S, Petropoulos CJ. Multiple genetic pathways involving amino acid position 143 of HIV-1 integrase are preferentially associated with specific secondary amino acid substitutions and confer resistance to raltegravir and cross-resistance to elvitegravir. Antimicrob Agents Chemother. 2013;57:4105-13.

41. Geretti AM, Armenia D, Ceccherini-Silberstein F. Emerging patterns and implications of HIV-1 integrase inhibitor resistance. Curr Opin Infect Dis. 2012;25:677-86

42. Wainberg MA, Mesplede T, Quashie PK. The development of novel HIV integrase inhibitors and the problem of drug resistance. Curr Opin Virol. 2012;2:656-62
43. Winters MA, Lloyd Jr RM, Shafer RW, Kozal MJ, Miller MD, Holodniy M. Development of elvitegravir resistance and linkage of integrase inhibitor mutations with protease and reverse transcriptase resistance mutations. PLoS One. 2012;7:e40514.

44. Mesplede T, Quashie PK, Wainberg MA. Resistance to HIV integrase inhibitors. Curr Opin HIV AIDS. 2012:7:401-8.

45. Garrido C, Villacian J, Zahonero N, Pattery T, Garcia F, Gutierrez F, et al. Broad phenotypic cross-resistance to elvitegravir in HIV-infected patients failing on raltegravir-containing regimens. Antimicrob Agents Chemother. 2012;56:2873-8

46. Blanco JL, Varghese V, Rhee SY, Gatell JM, Shafer RW. HIV-1 integrase inhibitor resistance and its clinical implications. J Infect Dis. 2011;203:1204-14.

47. Kobayashi M, Yoshinaga T, Seki T, Wakasa-Morimoto C, Brown KW, Ferris R, et al. In vitro antiretroviral properties of S/GSK1349572, a next-generation HIV integrase inhibitor. Antimicrob Agents Chemother. 2011;55:813-21.

48. da Silva D, Van Wesenbeeck L, Breilh D, Reigadas S, Anies G, Van Baelen K, et al. HIV-1 resistance patterns to integrase inhibitors in antiretroviral-experienced patients with virological failure on raltegravir-containing regimens. J Antimicrob Chemother. 2010;65:1262-9.

49. Goethals O, Clayton R, Van Ginderen M, Vereycken I, Wagemans E, Geluykens $\mathrm{P}$, et al. Resistance mutations in human immunodeficiency virus type 1 integrase selected with elvitegravir confer reduced susceptibility to a wide range of integrase inhibitors. J Virol. 2008;82:10366-74.

50. Marinello J, Marchand C, Mott BT, Bain A, Thomas CJ, Pommier Y. Comparison of raltegravir and elvitegravir on HIV-1 integrase catalytic reactions and on a series of drug-resistant integrase mutants. Biochemistry. 2008;47:9345-54.

51. Charpentier C, Larrouy L, Collin G, Damond F, Matheron S, Chene G, et al. In-vitro phenotypic susceptibility of HIV-2 clinical isolates to the integrase inhibitor S/GSK1349572. AIDS. 2010;24:2753-5.

52. Tivicay Package Insert. [http://www.gsksource.com/gskprm/htdocs/ documents/TIVICAY-PI-PIL.PDF]

53. Underwood MR, Johns BA, Sato A, Martin JN, Deeks SG, Fujiwara T. The activity of the integrase inhibitor dolutegravir against HIV-1 variants isolated from raltegravir-treated adults. J Acquir Immune Defic Syndr. 2012;61:297-301.

54. Canducci F, Ceresola ER, Boeri E, Spagnuolo V, Cossarini F, Castagna A, et al. Cross-resistance profile of the novel integrase inhibitor Dolutegravir (S/GSK1349572) using clonal viral variants selected in patients failing raltegravir. J Infect Dis. 2011;204:1811-5.

55. Canducci F, Ceresola ER, Saita D, Castagna A, Gianotti N, Underwood M, et al. In vitro phenotypes to elvitegravir and dolutegravir in primary macrophages and lymphocytes of clonal recombinant viral variants selected in patients failing raltegravir. J Antimicrob Chemother. 2013;68:2525-32.

56. Mesplede T, Osman N, Wares M, Quashie PK, Hassounah S, Anstett K, et al. Addition of E138K to R263K in HIV integrase increases resistance to dolutegravir, but fails to restore activity of the HIV integrase enzyme and viral replication capacity. J Antimicrob Chemother. 2014;69:2733-40.

57. Carganico A, Dupke S, Ehret R, Berg T, Baumgarten A, Obermeier M, et al. New dolutegravir resistance pattern identified in a patient failing antiretroviral therapy. J Int AIDS Soc. 2014;17:19749.

58. Cutillas V, Mesplede T, Anstett K, Hassounah S, Wainberg MA. The addition of R262K to the H51Y mutation in HIV-1 subtype B integrase confers low-leve resistance against dolutegravir. Antimicrob Agents Chemother. 2014;59:310-6.

59. Mesplede T, Quashie PK, Osman N, Han Y, Singhroy DN, Lie Y, et al. Vira fitness cost prevents HIV-1 from evading dolutegravir drug pressure. Retrovirology. 2013;10:22

60. Quashie PK, Mesplede T, Han YS, Oliveira M, Singhroy DN, Fujiwara T, et al. Characterization of the R263K mutation in HIV-1 integrase that confers low-leve resistance to the second-generation integrase strand transfer inhibitor dolutegravir. J Virol. 2012;86:2696-705.

61. Wares M, Mesplede T, Quashie PK, Osman N, Han Y, Wainberg MA. The M50I polymorphic substitution in association with the R263K mutation in HIV-1 subtype B integrase increases drug resistance but does not restore viral replicative fitness. Retrovirology. 2014;11:7.

62. Eron JJ, Clotet B, Durant J, Katlama C, Kumar P, Lazzarin A, et al. Safety and efficacy of dolutegravir in treatment-experienced subjects with raltegravir-resistant HIV type 1 infection: 24-week results of the VIKING Study. J Infect Dis. 2013;207:740-8.

63. Hardy I, Brenner B, Quashie P, Thomas R, Petropoulos C, Huang W, et al. Evolution of a novel pathway leading to dolutegravir resistance in a patient harbouring $\mathrm{N} 155 \mathrm{H}$ and multiclass drug resistance. J Antimicrob Chemother. 2014;70:405-11. 
64. Castagna A, Maggiolo F, Penco G, Wright D, Mills A, Grossberg R, et al. Dolutegravir in antiretroviral-experienced patients with raltegravir- and/or elvitegravir-resistant HIV-1: 24-week results of the phase III VIKING-3 study. J Infect Dis. 2014;210:354-62.

65. Trevino A, Cabezas T, Lozano AB, Garcia-Delgado R, Force L, Fernandez-Montero $J M$, et al. Dolutegravir for the treatment of HIV-2 infection. J Clin Virol. 2015;64:12-5.

66. Descamps D, Peytavin G, Damond F, Tubiana R, Campa P, Khuong MA, et al. Dolutegravir in the French Early Access Program in Integrase HIV-2-Resistant Infected Patients. 21st Conference on Retroviruses and Opportunistic Infections; 3-6 March 2014; Boston, MA.

67. Gottlieb GS, Smith RA, Dia Badiane NM, Ba S, Hawes SE, Toure M, et al. HIV-2 integrase variation in integrase inhibitor-naive adults in Senegal, West Africa. PLoS One. 2011;6:e22204.

68. Foley B, Leitner T, Apetrei C, Hahn B, Mizrachi I, Mullins J, et al. HIV Sequence Compendium 2013. Los Alamos, NM: Theoretical Biology and Biophysics Group, Los Alamos National Laboratory; 2013.

69. Fikkert V, Hombrouck A, Van Remoortel B, De Maeyer M, Pannecouque C, De Clercq $\mathrm{E}$, et al. Multiple mutations in human immunodeficiency virus-1 integrase confer resistance to the clinical trial drug S-1360. AIDS 2004;18:2019-28.

70. Kobayashi M, Nakahara K, Seki T, Miki S, Kawauchi S, Suyama A, et al. Selection of diverse and clinically relevant integrase inhibitor-resistant human immunodeficiency virus type 1 mutants. Antiviral Res. 2008;80:213-22.

71. Nguyen TT, Rato S, Molina JM, Clavel F, Delaugerre C, Mammano F: Impact of the HIV integrase genetic context on the phenotypic expression and in vivo emergence of raltegravir resistance mutations. J Antimicrob Chemother 2015. doi:10.1093/jac/dku424

72. Quashie PK, Oliviera M, Veres T, Osman N, Han Y, Hassounah S, et al. Differential effects of the G118R, H51Y and E138K resistance substitutions in HIV integrase of different subtypes. J Virol 2014. doi:10.1128/JVI.03353-14

73. Malet I, Gimferrer Arriaga L, Artese A, Costa G, Parrotta L, Alcaro S, et al. New raltegravir resistance pathways induce broad cross-resistance to all currently used integrase inhibitors. J Antimicrob Chemother. 2014;69:2118-22.

\section{Submit your next manuscript to BioMed Central and take full advantage of:}

- Convenient online submission

- Thorough peer review

- No space constraints or color figure charges

- Immediate publication on acceptance

- Inclusion in PubMed, CAS, Scopus and Google Scholar

- Research which is freely available for redistribution 